\title{
THE NATIVE ELM BARK BEETLE: PRIMARY VECTOR OF DUTCH ELM DISEASE IN SASKATCHEWAN.
}

ELENA SCHACHERL, Administrator Dutch Elm Disease Management

Program, Saskatchewan Environment and Resource Management, 112 Research Drive, Saskatoon, SK. S7K 2H6

Dutch Elm Disease (DED) has been present in North America since 1930, and has already destroyed millions of elm trees. First identified in Quebec in 1944, DED has been moving across Canada from east to west as well as northwards from the United States. The disease reached Manitoba in the 1970s.

In 1981 an isolated case of DED was found in Regina. DED was not detected again in the province until 1990 when it appeared in the Souris River valley near Estevan. Today this deadly disease is well-established in eastern Saskatchewan, with infection widespread in the Qu'Appelle, Souris, Pipestone, and Carrot River valleys.

Dutch Elm Disease is caused by a fatal fungus (Ceratocystis ulmi). The fungus triggers a chemical reaction that shuts down the water-conducting vessels of the elm tree. DED symptoms first show up in late June, sometimes later, particularly after a cold or wet spring. The leaves of an infected tree will droop or "flag," curl, and turn yellow or brown. Another sign of DED is the presence of brown staining or streaking under the bark of a suspect branch. Once

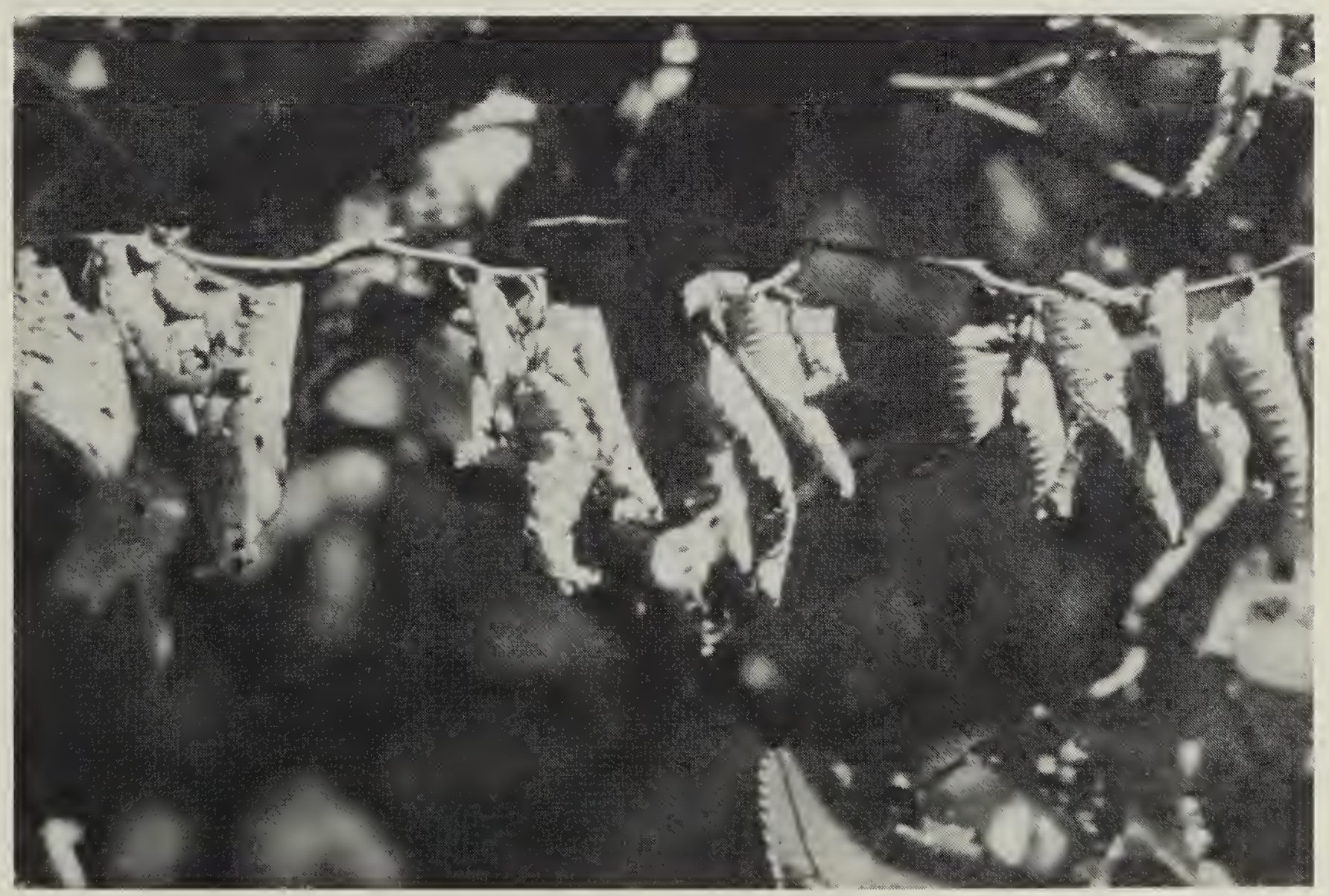




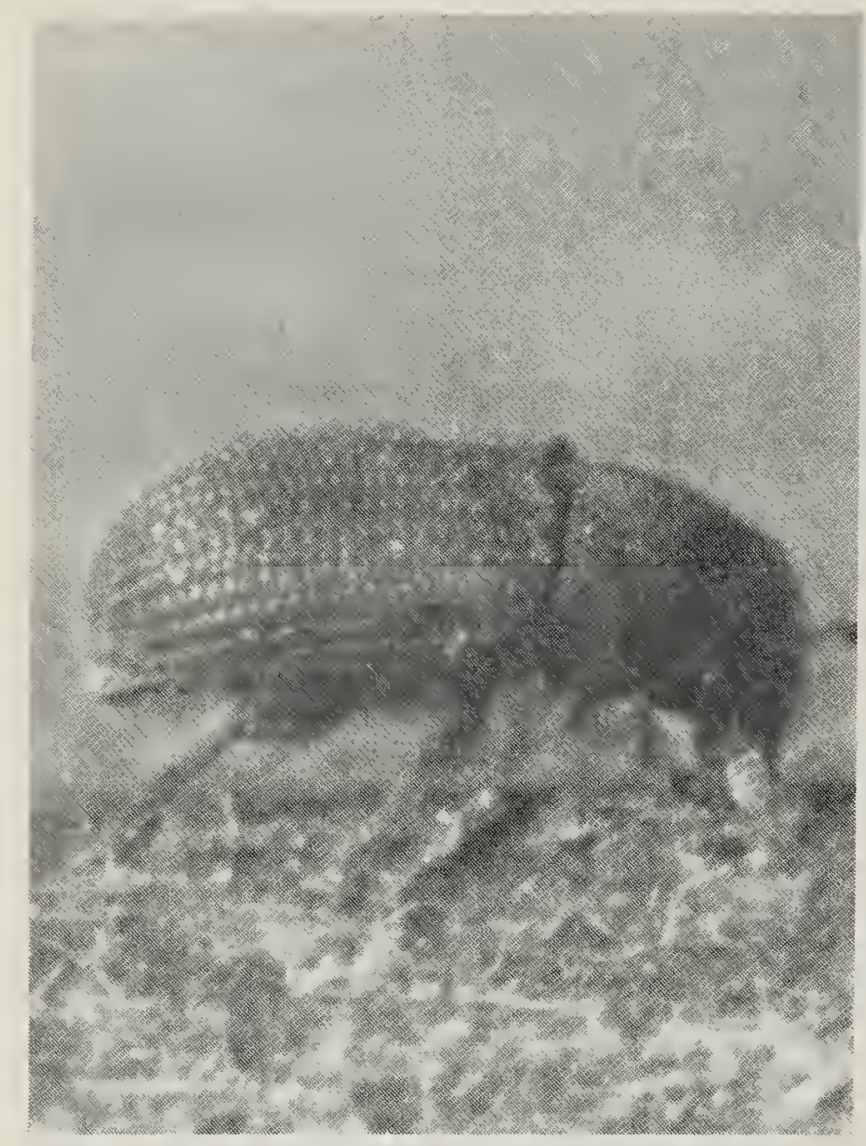

Adult Native Elm

Bark Beetle

Manitoba DNR

infected the tree will often die in as little as three weeks, and usually within a year.

American elm trees are most at risk, although some Siberian or Manchurian elms have also been known to become infected. They are also suspected of spreading the disease by serving as brood material for the beetle.

The primary vector of the disease in eastern Canada has been the European Elm Bark Beetle (Scolytus multistriatus). This species of beetle generally does not survive the colder prairie winters. Instead, in Saskatchewan the disease is usually carried by the hardier native Elm Bark Beetle (Hylurgopinus rufipes). This tiny beetle is only 2 to $3.5 \mathrm{~mm}$., about the size of the head of a pin.

The sticky spores of the DED fungus attach themselves to the beetle during its feeding, breeding, and overwintering activities. The beetle moves around spreading the disease by crawling, flying, or hitching a ride on elm wood, often destined for use as firewood. Strong prairie winds also contribute to the beetle's movement.

An overview of the life cycle of the native Elm Bark Beetle further illustrates how DED spreads from tree to tree. The new adult beetle first emerges in late July or early August at which time it feeds on elm branches. Anytime from late August to the end of September (depending on the weather) the beetle bores its way into the base of an elm tree, preferably a healthy one, where it overwinters. It does not emerge again until spring (April-May) at which time it feeds again for a few weeks, and then breeds.

Some of the later emerging adults may also breed before overwintering, but research on the native Elm Bark Beetle carried out by Manitoba Natural Resources has shown that gener. ally these overwintering larvae do not survive to adulthood. Some larvae may survive, however, in areas where the disease is poorly managed, as in wild elm stands.

The greatest incidence of DED infection occurs during the May and June summer feeding at which time the tree's vessels are most susceptible, although some infections may also occur in fall when the beetle overwinters. ${ }^{1}$ The native Elm Bark Beetle makes an ideal vector because it bores into the bark of the tree during both feeding and overwintering activities.

The beetle prefers to form its galleries and lay its eggs in dying elm wood or the branches or trunks of diseased trees. The galleries of the native Elm Bark Beetle are usually 


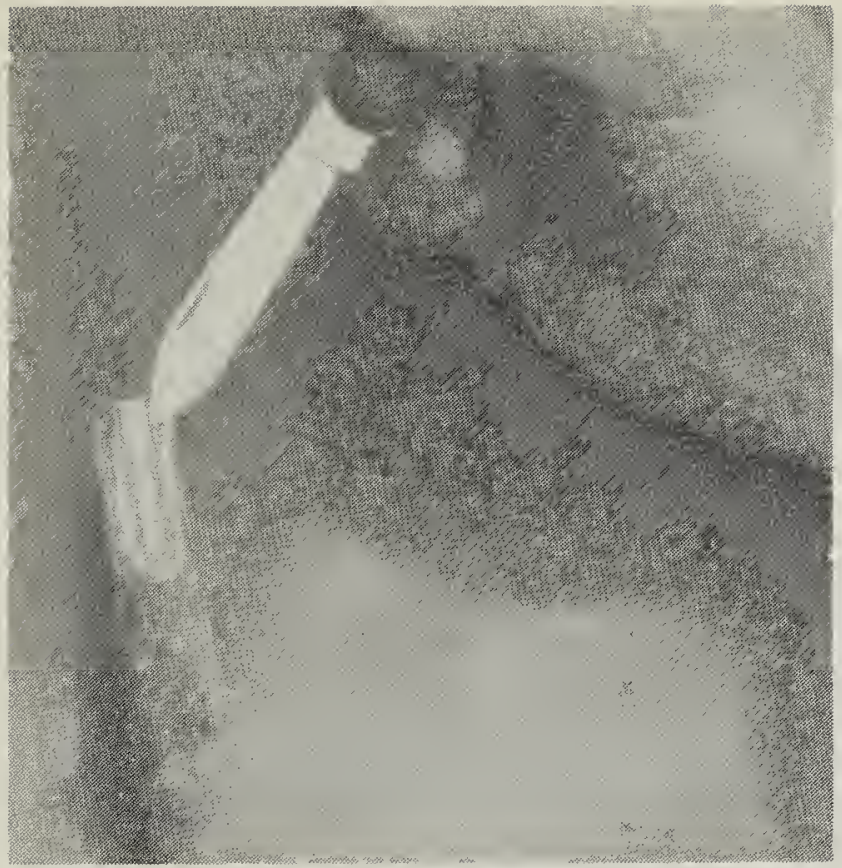

Wood staining - internal symptoms of DED

Manitoba DNR

horizontal, and the larval tunnels run with the wood grain. In contrast, the European Elm Bark Beetle bores its galleries vertically, and its tunnels run across the wood grain. The cut wood or tree needs to have at least $18 \%$ moisture content and its bark intact to be suitable brood material.

The life cycle of the native Elm

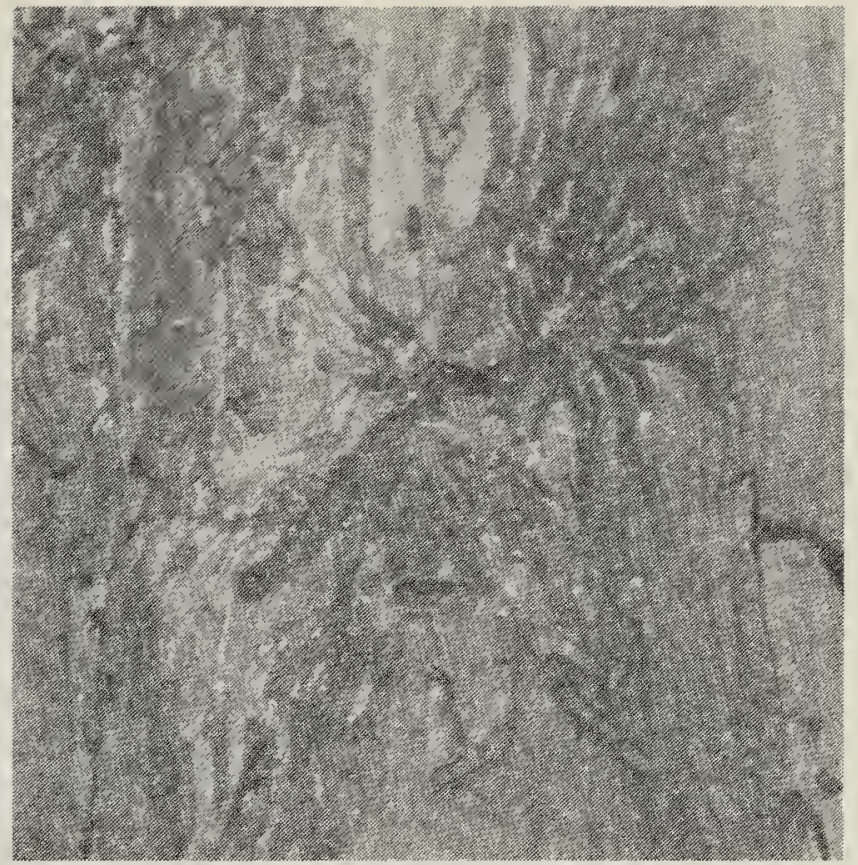

\section{Brood galleries of the Native}

Elm Baik Beetle

Manitoba DNR

Bark Beetle will vary with the particular season and the region. We know quite a bit about its behaviour in Manitoba and Minnesota, where the disease has been present for a couple of decades. We know less about its cycle in Saskatchewan, since the presence of DED is much more recent.

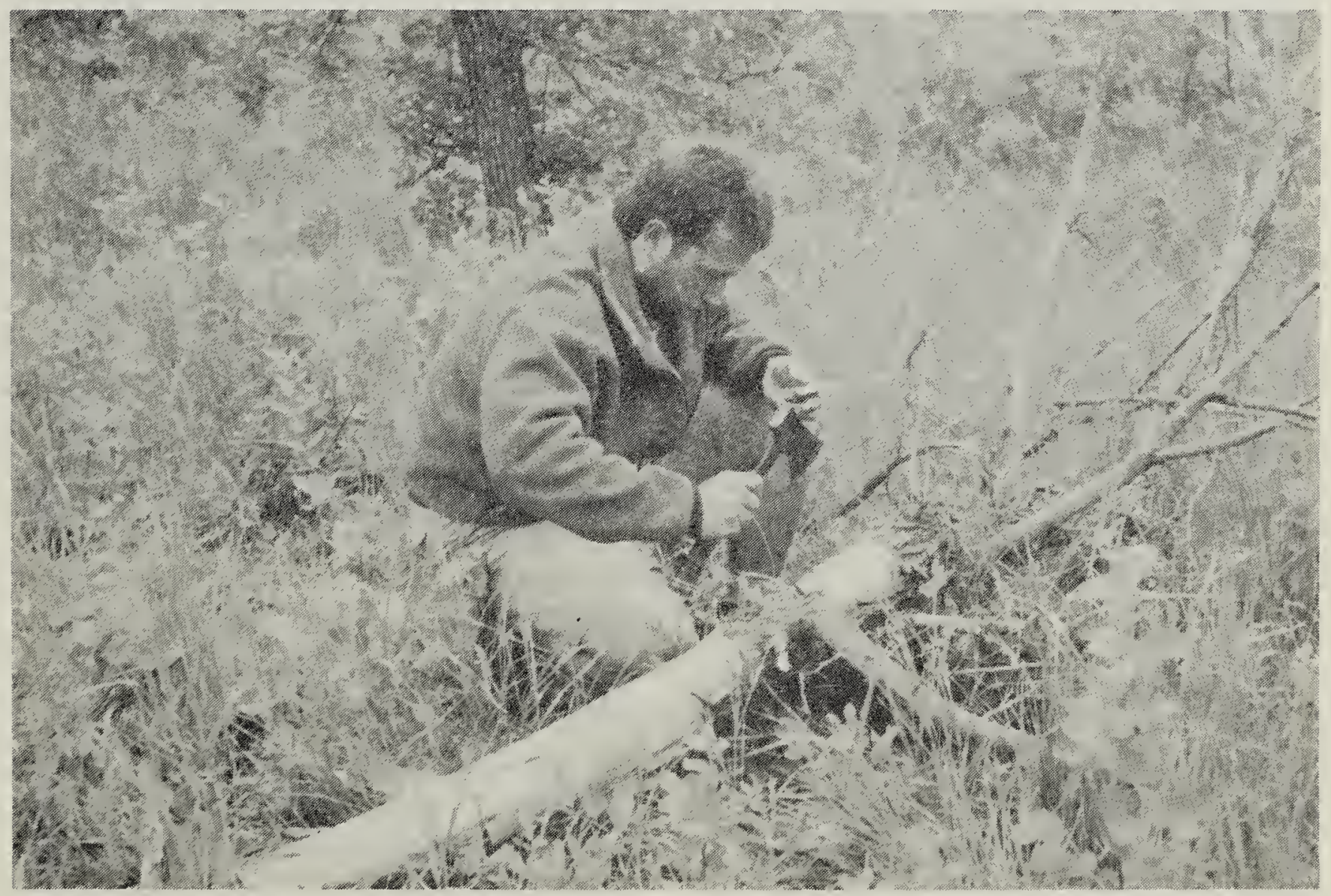




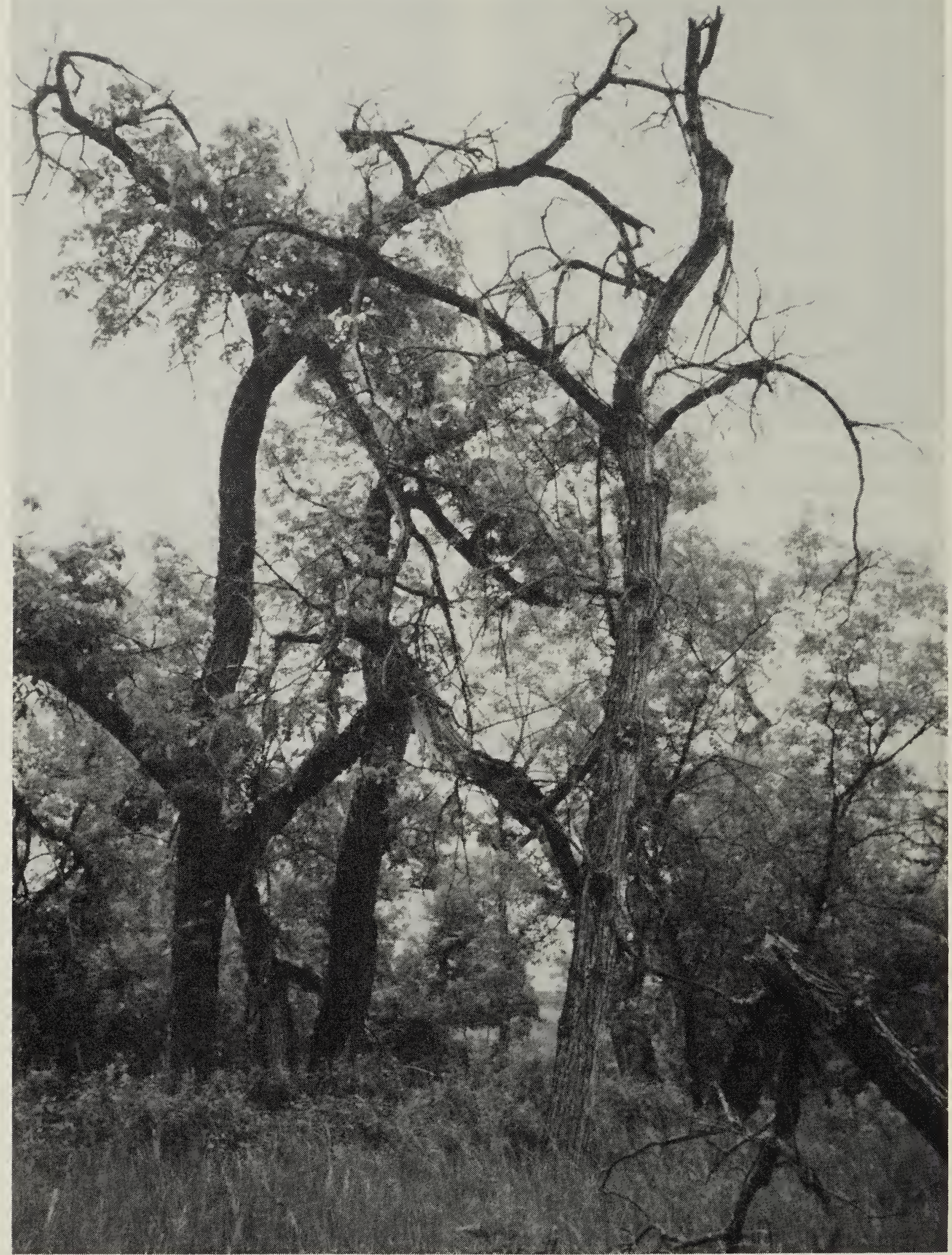

This year, for the first time, the Prairie Farm Rehabilitation Administration (PFRA) Shelterbelt Centre with the assistance of Saskatchewan Environment and Resource Management (SERM) and SOS Elms has undertaken a research project on the life history of the native Elm Bark
Beetle in Saskatchewan. The project was initiated to find out more about the beetle's behaviour pattern in this province, particularly such activities as emergence, breeding, and overwintering. Two test sites were set up near Trossachs and Whitewood. Part of the research has involved testing 
various pheromone lures and trapping methods, to determine which are most effective in attracting the beetle.

The life cycle research will provide information needed to carry out effective DED management. Overwintering and emergence dates, for example, help determine when to spray. Chemical control can be used to reduce the beetle population, particularly when done on a communitywide basis. The chemical chlorpyrifos (Dursban Turf) is applied by a licensed applicator to the bottom few feet of elm trees, including above ground root flares. The best time to spray is late August or early September before overwintering takes place, but spraying can also be done early in April before the beetle emerges.

To prevent the spread of DED, provincial legislation in the form of The Dutch Elm Disease Regulations make it illegal to store or transport elm wood of any kind. Whether branches, firewood, or a DEDinfected tree, all elm wood must be disposed of promptly by burning or burial in a designated disposal site.
This limits the spread of disease outside of infected areas, as well as restricting brood material.

Fresh pruning cuts lure the beetle to a tree, and for this reason there is an annual elm tree pruning ban in effect from 13 April to 31 July. Once the ban is over, municipalities and landowners are required under the DED regulations to prune all dead and dying wood from their elm trees.

It will take years of research before we have a better understanding of the life pattern of the native Elm Bark Beetle in Saskatchewan. Knowledge about this DED vector is an essential component in the fight to save Saskatchewan's majestic American Elms from the ravages of Dutch Elm Disease.

To find out more about Dutch Elm Disease and what you can do to help save our elm trees, call 1-800SASKELM (1-800-727-5356).

1. ASCERNO, MARK E., AND R. P. WAWRZYNSKI. 1993. Native EIm Bark Beetle Control. Minnesota Extension Service, University of Minnesota, College of Agriculture.

To summarize the present global pattern, latitudinal diversity gradients rising toward the tropics are an indisputable general feature of life. And on the land biodiversity is heavily concentrated in the tropical rain forests. So immense are the insect faunas alone in these forests, comprising possibly tens of millions of species, overwhelming even the opulence of the coral reefs, that on this basis alone it is reasonable to suppose that over half of all species are found there. E.O. Wilson, 1992. The diversity of life. W.W. Norton and Company, New York. 424 pp. 